\title{
Biofilm Related to Animal Health, Zoonosis and Food Transmitted Diseases: Alternative Targets for Antimicrobial Strategy?
}

\section{Domenico Schillaci ${ }^{1 *}$ and Maria Vitale ${ }^{2}$}

${ }^{1}$ Department of STEMBIO, Università degli Studi di Palermo, Via Archirafi 32, 90123-Palermo, Italy ${ }^{2}$ Istituto Zooprofilattico Sperimentale della Sicilia (IZS) “A. Mirri”, Via Gino Marinuzzi 3, 90129-Palermo, Italy

The biofilm is a complex community of microbial cells that are associated with a surface and enclosed in a self-produced biopolymer matrix. Such structured community is a response of bacteria to a signal system named quorum sensing (QS) constituted by inter-cell communication through the production of small molecules called autoinducers (AIs) that trigger a cascade of events in gene expression. When the concentration of the AIs molecules reach a certain threshold, the bacterial population acts as a single organism, collectively expressing virulence or biofilm forming genes. Gram-positive bacteria use modified oligopeptides as QS effectors molecules [1].

In Gram-negative bacteria, the signal molecules are acylhomoserine lactones (AHLs) which are also called auto-inducer 1 (AI-1). These two types of auto-inducers are considered to be responsible for intraspecies communication. A further QS system has been discovered in which a furanosyl borate ester, the auto-inducer 2 (AI-2), is used as effector [2]. AI-2 has been described in more than 50 Gram-positive and negative bacterial species, and it is considered responsible for inter-species communications $[3,4]$.

The pathogenic role of bacterial biofilms is a well known story in human health, because they are involved in chronic infections and Biomaterial Associated Infections (BAI) [5], but the role of biofilms in animal health and husbandry has been explored only in the last decade. Since biofilms can be found in virtually all natural ecosystems that can support microbial growth, they must have enormous impact in the veterinary world since they can be responsible for the failure in antimicrobial therapy in bacterial infections and of properly sanitations in food processing plants. Conventional antibiotics and sanitation procedures can be efficacious against planktonic (free living) pathogens but are quite often poorly effective against the bacteria organized in community. The biofilms show a high degree of intrinsic resistance to current antibiotics and sanitising agents [6], they allow the microorganisms to persist in the environment and to resist desiccation and UV light. Biofilms can be difficult to control since they are present where water is plentiful and cleaning is not performed properly.

The capability to organise a biofilm community is present in almost all Gram-negative and Gram -positive bacteria and several of them can be transmitted by feed or food and be highly pathogenic for animals and human beings.

Several pathogens such as Gram negative Campylobacter spp., Salmonella typhimurium, Pseudomonas aeruginosa, and Gram positive Staphylococcus spp. Listeria monocytogenes, use quorum sensing and biofilm formation as a mean to optimize virulence gene expression and host colonization.

Campylobacter jejuni is the most reported cause of food-borne gastrointestinal disease in the European Union, mainly due to the consumption of contaminated poultry meat. This bacterial species is anaerobic but surprisingly it is able to survive on the surface of meat in an oxygen-rich atmosphere. Recently it has been reported that the ability of C. jejuni to form biofilm is important to survive in a hostile environment. These bacteria can make its own community in aerobic conditions [7] or also can exploit the biofilm of other bacteria like Pseudomonas spp [8]. Campylobacter spp. has been found to attach to biofilms, which are found in the watering supplies and plumbing system of animal husbandry facilities and animal-processing plants, it also has the ability to form biofilm on stainless steel, glass, or polyvinyl chloride in vitro [9].

Salmonella ssp. is rich in several QS systems and some of them are capable of detecting effector molecules from other enterobacteria [10]. In Salmonella typhimurium the synthesis of a type 2 auto-inducer (AI2) is involved in its virulence [11]. Biofilm forming abilities of Salmonella are correlated with its persistence in fishmeal and feed factories. Feed contaminated with Salmonella spp. constitutes a risk of Salmonella infections in animals, and subsequently in the consumers of food of animal origins. Salmonella spp. is occasionally isolated from the feed factory environment and some clones of Salmonella persist in the factory environment for several years. Studies on Salmonella in fish factories suggest that biofilm forming ability may be an important factor for the persistence of Salmonella in the environment [12].

S. enteritidis is the most common serotype isolated in poultry farm and is responsible of many cases of food poisoning in human beings worldwide. Almost $50 \%$ of them are able to produce biofilm. The use of glutaraldehyde, formaldehyde, and peroxygen at a concentration of $1.0 \%$ in field conditions are inadequate for Salmonella elimination [13]

$P$. aeruginosa is notorious for its capability to form strong and mature biofilms and it is found ubiquitously on all wet surfaces. All kinds of animal tissues, plants and inert surfaces, can be colonized with a $P$. aeruginosa biofilm, thereby increasing environmental persistence [14]. In the veterinary medicine $P$. aeruginosa biofilms are probably involved in several cases of implanted device-associated infections [15] Biofilm formation is a severe complicating factor in cases of equine ulcerative keratitis and in dermatitis, otitis and urinary tract infections in small animals $[16,17]$. It can also be responsible for some forms of bovine mastitis, which are often associated with contaminated udder washing water or contaminated intramammary dry-cow preparations [18].

*Corresponding author: Domenico Schillaci, Department of STEMBIO Università degli Studi di Palermo, Via Archirafi 32, 90123-Palermo, Italy, Tel: +3909123891914; E-mail: domenico.schillaci@unipa.it

Received September 21, 2012; Accepted September 22, 2012; Published September 25, 2012

Citation: Schillaci D, Vitale M (2012) Biofilm Related to Animal Health, Zoonosis and Food Transmitted Diseases: Alternative Targets for Antimicrobial Strategy? J Microbial Biochem Technol 4: vii-x. doi:10.4172/1948-5948.1000e108

Copyright: (c) 2012 Schillaci D, et al. This is an open-access article distributed under the terms of the Creative Commons Attribution License, which permits unrestricted use, distribution, and reproduction in any medium, provided the original author and source are credited 
Horse wounds have a high risk of becoming infected and harbour diverse populations of microorganisms. Some infecting microorganisms can be difficult to identify and/or fail to respond to antibiotic treatment, resulting in chronic non-healing wounds. In human wounds this has been attributed to the ability of bacteria to survive in a biofilm phenotypic state that delay wound healing, principally due to their tolerance to current antibiotics and host immune response. The presence of biofilms in equine wounds partly explains the reluctance to heal of many lower limb wounds. Nonhealing limb wounds in horses are a well-documented welfare and economic concern. Novel treatments to control the biofilm formation could have a great impact in terms of increasing the healing rate, decreasing the cost of the treatment and, more importantly, for animal welfare reasons [19].

S. aureus is the most frequently isolated bacterium from ruminant intramammary infections, worldwide. The agr (accessory gene regulator) QS system is one of the most studied QS mechanisms in Gram-positive bacteria. S. aureus is divided into four different agr specific groups, by sequence analysis. Several virulence factors like enterotoxins, haemolysins, etc. are regulated by agr. Strains from bovine mastitis cases are predominantly classified in agr group I and to a lesser extent in agr groups II and III [20]. Bovine S. aureus strains belonging to agr group I show significantly increased capacities to be internalized in bovine mammary epithelial cells and persist in higher numbers in murine mammary glands [21], while agr group II strains might prefer the extracellular niche and therefore might be more dependent on biofilm formation. In addition, it has been suggested that penicillin resistance in bovine $S$. aureus strains is correlated to the presence of agr group I genes [22]. In contrast, for example, to $P$. aeruginosa, in $S$. aureus the main QS system agr important for its virulence seems to have a negative role on biofilm formation. AGR dependent expression contributes to the detachment of biofilms and subsequent colonization of new sites, acting positively in bacterial spreading [23]. Therefore, although still speculative, the QS dependent detachment from biofilms may render some $S$. aureus strains more capable of spreading through a herd, causing more chronic problems at the herd level. This may also explain why agr+ and agr-variants of $S$. aureus might have a cooperative interaction in certain types of infections [24].

Listeria monocytogenes is ubiquitous in nature and a major concern for the food-manufacturing sector, since it is the causal agent of the serious food-borne illness listeriosis. It is of big concern in the dairy industry also for its capability to multiply at refrigerator temperature and to survive at freezer temperatures. The common sites for $L$. monocytogenes isolation from dairy industry processing plants are the filling or packaging equipment, and a variety of facilities used for assembling the products for packaging, racks for transporting products, hand tools or gloves, and freezers [25].

L. monocytogenes may grow in biofilms that protect them against environmental stress and can be isolated from the work-surfaces even after cleaning and disinfection procedure. For each individual foodprocessing plant, a limited number of clones of L. monocytogenes may become established and persist for years [26]. Persistent strains adhere to surfaces and form biofilms more readily compared to sporadically found strains, suggesting that the adherence to the surfaces is important for the survival and persistence in food-processing environments. Several novel approaches to avoid adhesion of L. monocytogenes have been proposed, but high costs, practical difficulties or resistance problems limit their practical use. Despite considerable research on the adhesive properties and resistance of L. monocytogenes enabling its survival in the food production environment, a final solution for avoiding establishment of the bacterium has not yet been found [27].

The key transcriptional activator $\operatorname{PrfA}$ positively regulates $L$. monocytogenes virulence genes to mediate the transition from extracellular, flagellum-propelled cell to intracellular pathogen. There is evidence that PrfA has also a significant positive impact on extracellular biofilm formation. Mutants lacking $\operatorname{prfA}$ were defective in surface-adhered biofilm formation. The Delta $p r f A$ mutant exhibited wild-type flagellar motility, and its biofilm defect occurred after initial surface adhesion [28].

The brief excursus of five of the main pathogenic bacteria for humans present in the veterinary field probably suggests that the role of biofilm should be more carefully addressed in this field. Important topics in public health, such as food safety, zoonotic disease control and animal health and welfare are highly dependent on the capability to control bacterial biofilm and quorum sensing.

A better understanding of QS and the detection of autoinducers in veterinary medicine and in the food manufacturing sector may help in designing new approaches to tackle microbial persistence and biofilm formation. The bacterial quorum sensing has been implicated in the onset of bacterial pathogenicity [29], the signal molecules produced by the bacterial pathogens for the intra and inter-species communications can be used as potential biomarkers for the diagnosis and follow-up of bacterial infections. Because the chemical structure of the various signal molecules differs greatly, different sensory systems for detecting these molecules have been described [30-32]. Most of the studies dealing with QS signal molecules, however, focus on the detection of AHLs, of Pseudomonas aeruginosa or Burkholderia cepacia, the main bacterial species involved in the development of chronic infections in the lungs of cystic fibrosis patients in human medicine [33]. Despite the plethora of analytical systems, only a fraction can be used to detect QS signal molecules in clinical samples [34] and AHLs of various Gram-negative bacterial pathogens are measured in many human biological samples (sputum, muco purulent secretions of the respiratory tract, lung, etc), as a means to detect early stage of bacterial infections. Currently, there are not many reports of detection of QS signal molecules of bacterial pathogens in animal clinical samples and in samples of animal food products but this aspect could be very important in the veterinary field [35].

The concept of the inhibition of QS mechanism is also used by a range of prokaryotic and eukaryotic organisms as natural, physiological, self-defence mechanisms. Some $S$. aureus strains for example, produce auto-inducers that stimulate their own QS mechanisms, but have a cross inhibitory effect on the QS systems of other strains probably to exclude them from the colonization of common sites. Certain Bacillus sp. harbours enzyme, which inactivates AHL activity by specifically hydrolysing the lactone bond of AHLs of competing bacterial species [36]. The fact that certain human cell lines are able to inactivate QS signal molecules suggests that mammalian host defence might have developed interfering QS systems against bacterial infections as well [37].

It is clear that QS is a key regulatory system in the pathogenesis of various bacterial infections and is widely used by several bacterial species involved in animal health and in food-borne infections [38] Therefore, the targeting of the QS mechanisms provides a novel strategy 
Citation: Schillaci D, Vitale M (2012) Biofilm Related to Animal Health, Zoonosis and Food Transmitted Diseases: Alternative Targets for Antimicrobial Strategy? J Microbial Biochem Technol 4: vii-x. doi:10.4172/1948-5948.1000e108

for combating bacterial infections. These compounds have no direct effect on bacterial growth, but attenuate the virulence of the bacteria, with a consequent increase of the susceptibility of the pathogen to the host defences. This mechanism is very important in avoiding the raise of antimicrobial resistance, since no selective pressure is present for drug resistant strains contrarily to antibiotic treatment. Since QS probably plays a role in the pathogenesis of many bacterial infections in animals, two possible strategies could be actuated:

a) The detection of QS signals molecules at early stages of the infection with a consequent early intervention for the management of the infection.

b) The use of QS inhibitors for the treatment that may provide new tools in the future in human and in veterinary medicine as well.

In conclusion, many aspects in animal health and food-borne diseases should be reconsidered in light of the pathogens' ability to form biofilms and to perform cell-cell communication. Antimicrobial strategy in sanitization and in the treatment of infections specifically intended for the complete eradication of biofilm of the pathogenic bacteria, and not only to their planktonic form, could be an effective means to reaching better animal health and better bio-safety in farms and in food processing plants with a lower risk for the consumers.

\section{Acknowledgment}

The Authors would like to thank Dr Valeria Casale (On Point, Translation) for English revision of the manuscript.

\section{References}

1. Lyon GJ, Novick RP (2004) Peptide signaling in Staphylococcus aureus and other Gram-positive bacteria. Peptides 25: 1389-1403.

2. Surette MG, Miller MB, Bassler BL (1999) Quorum sensing in Escherichia coli, Salmonella typhimurium, and Vibrio harveyi: a new family of genes responsible for autoinducer production. Proc Natl Acad Sci USA 96: 1639-1644.

3. Schauder S, Shokat K, Surette MG, Bassler BL (2001) The LuxS family of bacterial autoinducers: biosynthesis of a novel quorum-sensing signal molecule. Mol Microbiol 41: 463-476.

4. Hardie KR, Heurlier K (2008) Establishing bacterial communities by 'word of mouth': LuxS and autoinducer 2 in biofilm development. Nat Rev Microbiol 6: 635-643.

5. Hall-Stoodley L, Stoodley P (2009) Evolving concepts in biofilm infections. Cell Microbiol 11: 1034-1043.

6. Høiby N, Bjarnsholt T, Givskov M, Molin S, Ciofu O (2010) Antibiotic resistance of bacterial biofilms. Int J Antimicrob Agents 35: 322-332.

7. Gundogdu O, Mills DC, Elmi A, Martin MJ, Wren BW, et al. (2011) The Campylobacter jejuni transcriptional regulator Cj1556 plays a role in the oxidative and aerobic stress response and is important for bacterial survival in vivo. J Bacteriol 193: 4238-4249.

8. Teh KH, Flint S, French N (2010) Biofilm formation by Campylobacter jejun in controlled mixed-microbial populations. Int J Food Microbiol 143: 118-124.

9. Moe KK, Mimura J, Ohnishi T, Wake T, Yamazaki W, et al. (2010) The mode of biofilm formation on smooth surfaces by Campylobacter jejuni. $\mathrm{J}$ Vet Med Sci 72: 411-416

10. Michael B, Smith JN, Swift S, Heffron F, Ahmer BM (2001) SdiA of Salmonella enterica is a LuxR homolog that detects mixed microbial communities. J Bacteriol 183: 5733-5742.

11. Choi J, Shin D, Ryu S (2007) Implication of quorum sensing in Salmonella enterica serovar typhimurium virulence: the luxS gene is necessary for expression of genes in pathogenicity island 1. Infect Immun 75: 4885-4890.

12. Vestby LK, Møretrø T, Langsrud S, Heir E, Nesse LL (2009) Biofilm forming abilities of Salmonella are correlated with persistence in fish meal- and feed factories. BMC Vet Res 5: 20

13. Marin C, Hernandiz A, Lainez M (2009) Biofilm development capacity of Salmonella strains isolated in poultry risk factors and their resistance against disinfectants. Poult Sci 88: 424-431.

14. de Bentzmann S, Plésiat P (2011) The Pseudomonas aeruginosa opportunistic pathogen and human infections. Environ Microbiol 13: 1655-1665

15. Weese JS (2008) A review of multidrug resistant surgical site infections. Vet Comp Orthop Traumatol 21: 1-7.

16. Keller RL, Hendrix DV (2005) Bacterial isolates and antimicrobial susceptibilities in equine bacterial ulcerative keratitis (1993--2004). Equine Vet J 37: 207-211.

17. Rubin J, Walker RD, Blickenstaff K, Bodeis-Jones S, Zhao S (2008) Antimicrobial resistance and genetic characterization of fluoroquinolone resistance of Pseudomonas aeruginosa isolated from canine infections. Vet Microbiol 131: 164-172.

18. McLennan MW, Kelly WR, O'Boyle D (1997) Pseudomonas mastitis in a dairy herd. Aust Vet J 75: 790-792

19. Westgate SJ, Percival SL, Knottenbelt DC, Clegg PD, Cochrane CA (2011) Microbiology of equine wounds and evidence of bacterial biofilms. Vet Microbio 150: 152-159.

20. Vautor E, Magnone V, Rios G, Le Brigand K, Bergonier D, et al. (2009) Genetic differences among Staphylococcus aureus isolates from dairy ruminan species: a single-dye DNA microarray approach. Vet Microbiol 133: 105-114.

21. Melchior MB, Vaarkamp H, Fink-Gremmels J (2006) Biofilms: a role in recurrent mastitis infections? Vet J 171: 398-407.

22. Melchior MB, van Osch MH, Graat RM, van Duijkeren E, Mevius DJ, et al. (2009) Biofilm formation and genotyping of Staphylococcus aureus bovine mastitis isolates: evidence for lack of penicillin-resistance in Agr-type II strains. Vet Microbiol 137: 83-89.

23. Boles BR, Horswill AR (2008) Agr-mediated dispersal of Staphylococcus aureus biofilms. PLoS Pathog 4: e1000052.

24. Traber KE, Lee E, Benson S, Corrigan R, Cantera M, et al. (2008) agr function in clinical Staphylococcus aureus isolates. Microbiology 154: 2265-2274.

25. Pritchard TJ, Flanders KJ, Donnelly CW (1995) Comparison of the incidence of Listeria on equipment versus environmental sites within dairy processing plants. Int J Food Microbiol 26: 375-384.

26. Nucera D, Lomonaco S, Bianchi DM, Decastelli L, Grassi MA, et al. (2010) A five year surveillance report on PFGE types of Listeria monocytogenes isolated in Italy from food and food related environments. Int J Food Microbiol 140: 271-276.

27. Nilsson RE, Ross T, Bowman JP (2011) Variability in biofilm production by Listeria monocytogenes correlated to strain origin and growth conditions. Int Food Microbiol 150: 14-24.

28. Lemon KP, Freitag NE, Kolter R (2010) The virulence regulator PrfA promotes biofilm formation by Listeria monocytogenes. J Bacteriol 192: 3969-3976.

29. Girard G, Bloemberg GV (2008) Central role of quorum sensing in regulating the production of pathogenicity factors in Pseudomonas aeruginosa. Future Microbiol 3: 97-106.

30. Kumari A, Pasini P, Deo SK, Flomenhoft D, Shashidhar H, et al. (2006) Biosensing systems for the detection of bacterial quorum signaling molecules. Anal Chem 78: 7603-7609.

31. Steindler L, Venturi V (2007) Detection of quorum-sensing $\mathrm{N}$-acyl homoserine lactone signal molecules by bacterial biosensors. FEMS Microbiol Lett 266: 1-9.

32. Rajamani S, Zhu J, Pei D, Sayre R (2007) A LuxP-FRET-based reporte for the detection and quantification of Al-2 bacterial quorum-sensing signal compounds. Biochemistry 46: 3990-3997.

33. Baldrich E, Muñoz FX, García-Aljaro C (2011) Electrochemical detection of quorum sensing signaling molecules by dual signal confirmation at microelectrode arrays. Anal Chem 83: 2097-2103. 
Citation: Schillaci D, Vitale M (2012) Biofilm Related to Animal Health, Zoonosis and Food Transmitted Diseases: Alternative Targets for Antimicrobial Strategy? J Microbial Biochem Technol 4: vii-x. doi:10.4172/1948-5948.1000e108

34. Kumari A, Pasini P, Daunert S (2008) Detection of bacterial quorum sensing $\mathrm{N}$-acyl homoserine lactones in clinical samples. Anal Bioanal Chem 391: 16191627.

35. Sivakumar KK, Jesudhasan PR, Pillai SD (2011) Detection of autoinducer (Al2)-like activity in food samples. Methods Mol Biol 692: 71-82.

36. Dong YH, Wang LH, Xu JL, Zhang HB, Zhang XF, et al. (2001) Quenching quorum-sensing-dependent bacterial infection by an $\mathrm{N}$-acyl homoserine lactonase. Nature 411: 813-817.
37. Chun CK, Ozer EA, Welsh MJ, Zabner J, Greenberg EP (2004) Inactivation of a $P$ seudomonas aeruginosa quorum-sensing signal by human airway epithelia Proc Natl Acad Sci USA 101: 3587-3590.

38. Boyen F, Eeckhaut V, Van Immerseel F, Pasmans F, Ducatelle R, et al. (2009) Quorum sensing in veterinary pathogens: mechanisms, clinical importance and future perspectives. Vet Microbiol 135: 187-195. 